\title{
PF-2341066 combined with celecoxib promotes apoptosis and inhibits proliferation in human cholangiocarcinoma QBC939 cells
}

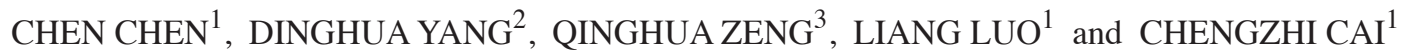 \\ ${ }^{1}$ Department of Hepatobiliary Surgery, Hunan Provincial People's Hospital, Changsha, Hunan 410002; \\ ${ }^{2}$ Department of Hepatobiliary Surgery, Nanfang Hospital, Southern Medical University, Guangzhou, Guangdong 510515; \\ ${ }^{3}$ Department of Rheumatology and Immunology, Hunan Provincial People's Hospital, Changsha, Hunan 410002, P.R. China
}

Received May 9, 2017; Accepted February 2, 2018

DOI: $10.3892 /$ etm.2018.5967

\begin{abstract}
Intrahepatic cholangiocarcinoma (ICC) is a malignant tumor with high incidence and an average age of onset of 50-70 years old. However, at present there is no effective treatment for this disease. The aim of the present study was to investigate the effects of a c-Met inhibitor, PF-2341066 and a cyclooxygenase-2 (COX-2) inhibitor, celecoxib, on c-Met and COX-2 expression, proliferation and apoptosis. The results demonstrated that c-Met and COX-2 are highly expressed in hepatobiliary calculus with cholangiocarcinoma. PF-2341066 was able to downregulate the expression of c-Met and COX-2 in a dose-dependent manner at the mRNA and protein levels in human cholangiocarcinoma QBC939 cells. Furthermore, combined treatment with PF-2341066 with celecoxib downregulated the mRNA expression of both genes, inhibited cell proliferation and promoted cell apoptosis. It was also demonstrated that PF-2341066 and celecoxib treatment was able to restrict the expression of vascular endothelial growth factor (VEGF). The results of the present study suggest that PF-2341066 and celecoxib may inhibit the development of cholangiocarcinoma by downregulating the expression of c-Met and COX-2 to inhibit cell proliferation, promote apoptosis and prevent VEGF-mediated tumor angiogenesis. Co-treatment with PF-2341066 and celecoxib may be a potential therapeutic strategy for hepatobiliary calculus with cholangiocarcinoma.
\end{abstract}

\section{Introduction}

Intrahepatic cholangiocarcinoma (ICC) is a type of malignant tumor with high incidence and an average age of onset of

Correspondence to: Dr Dinghua Yang, Department of Hepatobiliary Surgery, Nanfang Hospital, Southern Medical University, 1838 Guangzhou North Avenue, Guangzhou, Guangdong 510515, P.R. China

E-mail: dinghuayang01@163.com

Key words: hepatolithiasis, cholangiocarcinoma, c-Met, cyclooxygenase-2, PF-2341066, celecoxib
50-70 years old, the etiology of which remains to be elucidated. A previous study reported that patients with bile duct stones have a high incidence of cholangiocarcinoma; however, the clinical manifestations of ICC lack specificity and lead to delayed diagnosis and treatment (1).

c-Met is a receptor of hepatocyte growth factor (HGF), which serves a role in the regulation of cellular signaling transduction and cytoskeleton rearrangement, as well as cell division, proliferation, differentiation and migration (2). HGF is primarily produced by mesenchymal cells acting in an autocrine and paracrine manner and (3) PF-2341066 is a c-Met inhibitor that was approved by the United States Food and Drug Administration in 2011. PF-2341066 exhibits antiproliferative and antiangiogenic effects, suppressing the development of cancer by inhibiting the phosphorylation of c-Met and it's downstream signaling (4). It has previously been reported that c-Met signaling is important for the development of cholangiocarcinoma (5) and so PF-2341066 may be potential a candidate treatment for ICC. However, this conjecture remains unproven.

COX-2 is primarily distributed in the nuclear envelope of the nucleus and is able to promote cell proliferation, inhibit apoptosis and promote blood vessel formation, contributing to the pathogenesis of tumors $(6,7)$. Celecoxib is a selective inhibitor of COX-2 and has anti-angiogenesis effects (8). A previous study revealed that celecoxib is able to inhibit tumor formation via the vascular endothelial growth factor (VEGF) pathway (9). VEGF is one of the most potent and specific vascular growth factors that induce angiogenesis in the tumor microenvironment (10). VEGF promotes tumor angiogenesis and provides a matrix for the migration of vascular endothelial cells and the metastasis of tumor cells (5).

A previous study revealed that c-Met affects COX-2; HGF activates COX-2 expression via c-Met phosphorylation and the extracellular signal-regulated kinase-2 cell signal transduction pathway $(11,12)$. Selective COX-2 inhibitors, including celecoxib, may inhibit tumor growth by downregulating the expression of COX-2 and c-Met (13). However, whether c-Met inhibitors are able to regulate $\mathrm{COX}$-2-mediated signaling and the development of cholangiocarcinoma remains to be elucidated. Little is known about the expression profiles of COX-2 and c-Met in hepatobiliary calculus with cholangiocarcinoma (HCWC). 
The aim of the present study was to analyze the expression of COX-2 and c-Met in normal tissue (NT), hepatobiliary calculus tissue (HCT), paracarcinoma tissue (PT) and HCWC. The effect of PF-2341066 and celecoxib, which are c-MET and COX-2 inhibitors, respectively, on proliferation and apoptosis in human cholangiocarcinoma QBC939 cells was investigated. The results suggest that combined treatment with PF-2341066 and celecoxib may inhibit cell proliferation and promote cell apoptosis by downregulating the expression of c-Met, COX-2 and VEGF. Co-administration of c-MET and COX-2 may therefore have potential for the treatment of cholangiocarcinoma.

\section{Materials and methods}

Tissue samples. The present study was performed in strict accordance with the approval and recommendations of the Committee for Care and Use in Clinical Study of Hunan Provincial People's Hospital (C2016005). All patients provided written informed consent. A total of 90 patients with cholangiocarcinoma aged 40.1-68.5 years were recruited from January 2013 to January 2016 in the present study, with a follow-up period of 36 months. The sex ratio of patients was 47:43 (male:female). NT was obtained by performing a hepatic lobectomy in traumatic liver rupture. HCT was dissected from the tissues, which were $\geq 4 \mathrm{~cm}$ from the bossing. PT was obtained $2 \mathrm{~cm}$ away from the tumor tissue. HCWC was obtained directly from the tumor tissue. All samples were double checked by the naked eye and histological observation via hematoxylin and eosin (H\&E) staining. $1.5 \times 1.5 \mathrm{~cm}$ tissues were frozen at $-20^{\circ} \mathrm{C}$ via rapid intraoperative freezing and then cut into $1.5 \mu \mathrm{m}$-thick sections for H\&E staining for $45 \mathrm{~min}$ at room temperature. Ten tissue samples were obtained in each group. Tissues were, quickly stored in liquid nitrogen for use in the following experiments.

Cell culture. The cholangiocarcinoma cell line QBC939 was purchased from NanJing KeyGen Biotech Co., Ltd. (Nanjing, China) and cultured with 90\% RPMI 1640 medium supplemented with $10 \%$ fetal bovine serum for $48 \mathrm{~h}$ at $37^{\circ} \mathrm{C}$ in an atmosphere containing $5 \% \mathrm{CO}_{2}$. When a monolayer in the culture flask formed, cells were washed with PBS and digested with trypsin-EDTA (T4049; Sigma-Aldrich; Merck KGaA, Darmstadt, Germany) for $2 \mathrm{~min}$. The cell suspension was inoculated onto a culture plate for subsequent experiments. Cells were divided into the following six groups: Control group (no inhibitor treatment), 25 nM PF-2341066 (PZ0191; Sigma-Aldrich; Merck KGaA) treatment group, $50 \mathrm{nM}$

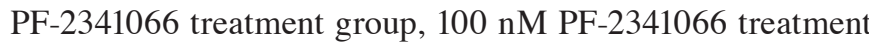
group, $200 \mathrm{nM}$ PF-2341066 treatment group, $100 \mathrm{nM}$ celecoxib (Y0001445; Sigma-Aldrich; Merck KGaA) treatment group and $100 \mathrm{nM}$ PF-2341066 $+100 \mu \mathrm{M}$ celecoxib treatment group. Cells were treated with the appropriate agents at $37^{\circ} \mathrm{C}$ for $48 \mathrm{~h}$ and collected for western blotting, reverse transcription-quantitative polymerase chain reaction (RT-qPCR), flow cytometry and MTT assays.

Western blotting. c-Met, COX-2 and VEGF proteins were detected using western blotting as previously described (11). Briefly, the cells were lysed with radioimmunoprecipitation assay lysis buffer (cat. no. P0013C; Beyotime Institute of Biotechnology, Haimen, China), total proteins were extracted and concentration was determined using a BCA assay (cat. no. P0009; Beyotime Institute of Biotechnology). A total of $50 \mu \mathrm{g}$ proteins were loaded per lane and subjected to $10 \%$ SDS-PAGE and electrotransferred to polyvinylidene fluoride membranes. Membranes were rinsed with TBS for 10-15 min and blocked with $5 \%(\mathrm{w} / \mathrm{v})$ skimmed milk powder at room temperature for $1 \mathrm{~h}$. Membranes were subsequently incubated with the following primary antibodies: Anti-c-Met (cat. no. ab51067), anti- $\beta$-actin (cat. no. ab8227), anti-COX-2 (cat. no. ab62331) and anti-VEGF (cat. no. ab46154; all Abcam, Cambridge, UK; all 1:1,000) at room temperature for $2 \mathrm{~h}$ and rinsed with TBST three times for 5-10 min. The membrane was then with a horseradish peroxidase-conjugated secondary antibody (SV0002; Wuhan Boster Biological Technology, Ltd., Wuhan, China; 1:10,000) at room temperature for $1 \mathrm{~h}$ and rinsed with TBST three times for 5-10 min. The protein bands were scanned and quantified as a ratio to $\beta$-actin. Target bands were visualized using a BeyoECL Plus kit (cat. no. P0018; Beyotime Institute of Biotechnology) according to the manufacturers' protocol and quantitatively analyzed using Quantity One software (version 4.6.2; Bio-Rad Laboratories, Inc., Hercules, CA, USA).

Detection of c-Met, COX-2 and VEGF mRNA expression by $R T-q P C R$. Cells were washed with RNase free PBS. Total RNA was extracted using RNeasy Mini kit (Qiagen GmbH, Hilden, Germany) according to the manufacturers' protocol and the concentration and purity were determined using a Qubit Fluorometer (Invitrogen; Thermo Fisher Scientific, Inc., Waltham, MA, USA) according to the manufacturers' protocol. A total of $1 \mu \mathrm{g}$ RNA was reverse transcribed at $42^{\circ} \mathrm{C}$ using a Reverse Transcription System kit (cat. no. A3500; Promega Corp., Madison, WI, USA) in accordance with the manufacturers' instructions. qPCR was performed using the SYBR Green PCR Master Mix (Qiagen AB, Sollentuna, Sweden). The primers used are listed in Table I. Thermocycling conditions were as follows: $95^{\circ} \mathrm{C}$ for $5 \mathrm{~min}$, followed by 40 cycles of $95^{\circ} \mathrm{C}$ for $30 \mathrm{sec}, 60^{\circ} \mathrm{C}$ for $45 \mathrm{sec}$ and $72^{\circ} \mathrm{C}$ for $30 \mathrm{sec}$. The relative mRNA expression levels were normalized to GAPDH and calculated using the $2^{-\Delta \Delta \mathrm{Cq}}$ method (14).

Detection of cell apoptosis using flow cytometry. Cell apoptosis was determined by flow cytometry using an Annexin V-fluorescein isothiocyanate (FITC)/propidium iodide (PI) apoptosis detection kit (KGA106; Nanjing KeyGen Biotech Co., Ltd., Nanjing, China) according to the manufacturer's protocol. Briefly, the cell suspension was washed with PBS and centrifuged at $1,000 \mathrm{xg}$ for $5 \mathrm{~min}$ at $4^{\circ} \mathrm{C}$. Cells were resuspended with binding buffer as provided by the kit and incubated at room temperature for 10-15 min. A total of $5 \mu \mathrm{l}$ Annexin V-FITC was added and mixed. Subsequently, $5 \mu 1$ PI was added and incubated at room temperature for 5-15 min. Results were detected using a flow cytometer.

Cell proliferation detection. Cell proliferation was assessed using an MTT assay. Cells were seeded in a 96-well plate at a density of $1 \times 10^{4}$ cells/well and plates were cultivated in an incubator for $24 \mathrm{~h}$ at $37^{\circ} \mathrm{C}$. A total of $50 \mu 1$ XX MTT (KGA311; 
Table I. Primers used for reverse transcription-quantitative polymerase chain reaction.

\begin{tabular}{lll}
\hline Gene & Direction & Primer sequence (3'-5') \\
\hline c-Met & Forward & AGCGTCAACAGAGGGACCT \\
& Reverse & GCAGTGAACCTCCGACTGTATG \\
Cyclooxygenase-2 & Forward & GATTGCCCGACTCCCTTGG \\
Vascular endothelial growth factor & Reverse & AAAACTGATGCGTGAAGTGCTG \\
& Forward & AGCCCATGAAGTGGTGAA \\
GAPDH & Reverse & TGCGGATCTTGGACAAAC \\
& Forward & TGACTTCAACAGCGACACCCA \\
& Reverse & CACCCTGTTGCTGTAGCCAAA
\end{tabular}

A
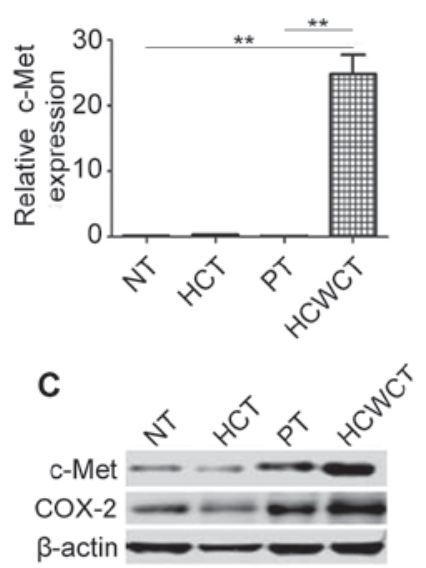

\section{B}

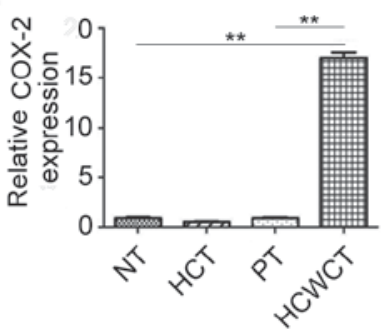

D

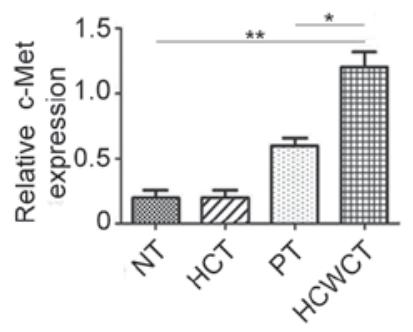

\section{E}

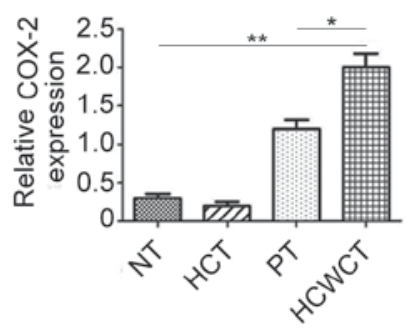

Figure 1. Expression of c-Met and COX-2 mRNA and protein. The expression of (A) c-Met and (B) COX-2 mRNA in NT, HCT, PT and HCWCT tissues was measured using reverse transcription-quantitative polymerase chain reaction. (C) Western blotting was performed to measure the expression of c-Met and COX-2. $\beta$-actin was used as the reference gene. The relative expression of (D) c-Met and (E) $\mathrm{COX}-2$ was calculated. ${ }^{*} \mathrm{P}<0.05$, ${ }^{* *} \mathrm{P}<0.01$. COX-2, cyclooxygenase-2; NT, normal tissue; HCT, hepatobiliary calculus tissue; PT, paracarcinoma tissue; HCWCT, hepatobiliary calculus with cholangiocarcinoma tissue.

NanJing KeyGen Biotech Co., Ltd.) was added to each well and cells were incubated for $4 \mathrm{~h}$ at $37^{\circ} \mathrm{C}$. The culture medium was discarded and $150 \mu \mathrm{l}$ dimethyl sulfoxide was added to each well. The plates were shaken for $10 \mathrm{~min}$ and the optical density (OD) was measured using a microplate reader at $550 \mathrm{~nm}$. The cell growth inhibition rate $=(1-$ mean OD value of treatment group/mean OD value of control group) x100.

Statistical analysis. Data are presented as the mean + standard deviation and were analyzed using SPSS 20.0 software (IBM Corp., Armonk, NY, USA). One-way analysis of variance was used to evaluate the differences between groups. $\mathrm{P}<0.05$ was considered to indicate a statistically significant difference.

\section{Results}

c-Met and COX-2 were highly expressed in hepatobiliary calculi with cholangiocarcinoma tissue. To investigate the expression of c-Met and COX-2 in cholangiocarcinoma, gene expression in NT, HCT, PT and HCWCT was measured using RT-qPCR. The results demonstrated that c-Met and COX-2 expression was significantly higher in HCWCT compared with NT and PT (Fig. 1A and B). Western blotting was performed to measure the expression of c-Met and COX-2 at the protein level and it was demonstrated that they were significantly upregulated in HCWCT compared with NT and PT (Fig. 1C-E). These results indicate that c-Met and COX-2 may serve a role in the development of cholangiocarcinoma.

PF-2341066 and celecoxib inhibit the expression of $c$-Met and COX-2 in a concentration-dependent manner in QBC939 cells. Human cholangiocarcinoma QBC939 cells were treated with PF-2341066 and celecoxib. The results demonstrated that treatment with PF-2341066 at a dose of $50 \mathrm{nM}$ or higher significantly inhibited the expression of c-Met and COX-2 at the mRNA level (Fig. 2A and B) in a dose-dependent manner. Western blotting revealed a similar effect at the protein level; treatment with $\geq 50 \mathrm{nM}$ PF-2341066 significantly 


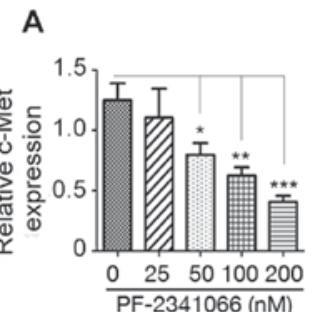

D

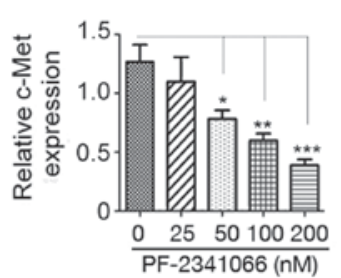

G

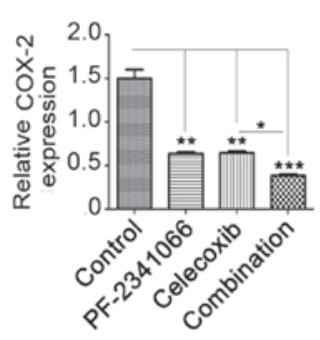

B

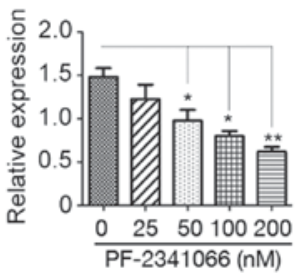

E

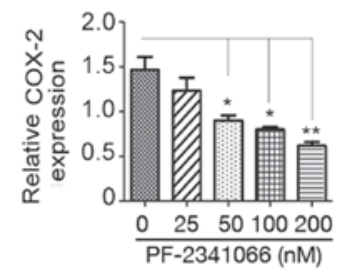

$\mathrm{H}$
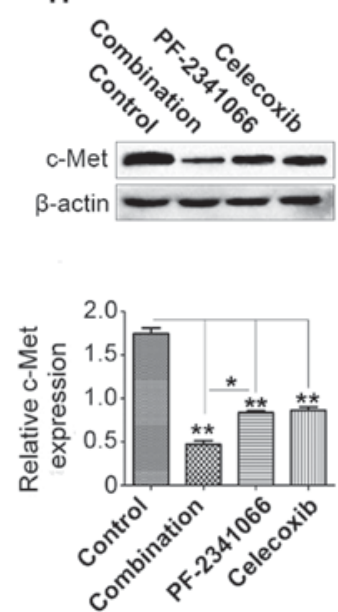

C

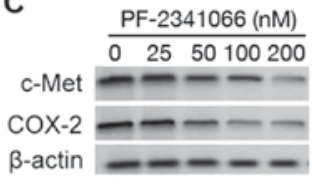

$\mathbf{F}$

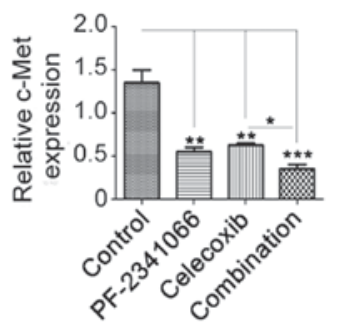

I
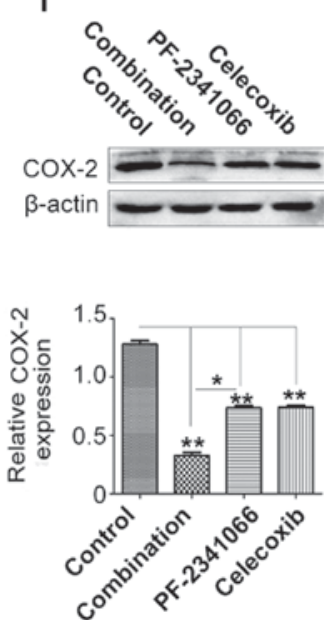

Figure 2. Expression of c-Met and COX-2 in human cholangiocarcinoma QBC939 cells following PF-2341066 and celecoxib treatment. The expression of (A) c-Met and (B) COX-2 mRNA following treatment with 0, 25, 100 and $200 \mathrm{nM}$ PF-2341066 was measured using RT-qPCR. (C) Western blotting was performed to measure the protein expression of (D) c-Met and (E) COX-2 following treatments. (F) c-Met and (G) COX-2 mRNA expression following treatment with PF-2341066 and celecoxib was measures using RT-qPCR. Western blotting was performed to measure the expression of (H) c-Met and (I) COX-2 following treatment. ${ }^{*} \mathrm{P}<0.05,{ }^{* *} \mathrm{P}<0.01$ and ${ }^{* * *} \mathrm{P}<0.001$. COX-2, cyclooxygenase-2; RT-qPCR, reverse transcription-quantitative polymerase chain reaction; Combination, treatment with $100 \mathrm{nM}$ PF-2341066 + $100 \mu \mathrm{M}$ celecoxib.

downregulated c-Met and COX-2 expression compared with $0 \mathrm{nM}$ (Fig. 2C-E). Combined treatment with PF-2341066 and celecoxib significantly suppressed the expression of COX-2 and c-Met, and this suppression was significantly greater than that observed with PF-2341066 treatment along (Fig. 2F- I). These results suggest that combined treatment with PF-2341066 and celecoxib inhibits the expression of c-Met and COX-2 at the transcription and translation levels and inhibition is improved by combined treatment.

PF-2341066 and celecoxib inhibit cell proliferation and promote cell apoptosis. The results described above indicated that PF-2341066 and celecoxib may inhibit cholangiocarcinoma by downregulating the expression of c-Met and COX-2. To further investigate this, the proliferation and apoptosis of QBC939 cells were measured following treatment with PF-2341066 and celecoxib. The results demonstrated that PF-2341066 significantly inhibits cell proliferation in a concentration-dependent manner (Fig. 3A) and promotes apoptosis in a dose-dependent manner (Fig. 3B and C). It was also observed that the increase in cell apoptosis was significantly greater with combined PF-2341066 and celecoxib treatment compared with PF-2341066 alone (Fig. 3D and E). In addition, combined treatment with PF-2341066 and celecoxib significantly increased cell growth inhibition compared with PF-2341066 alone (Fig. 3F). These results suggest that PF-2341066 and celecoxib inhibit proliferation and promote apoptosis in QBC939 cells and thereby may have potential as a therapeutic treatment for hepatobiliary calculus with cholangiocarcinoma.

VEGF expression was inhibited by PF-2341066 and celecoxib treatment. VEGF promotes tumor neovascularization, thereby providing a matrix for the migration of vascular endothelial cells and promoting tumor metastasis (15). To investigate whether PF-2341066 and celecoxib serve a role in inhibiting 

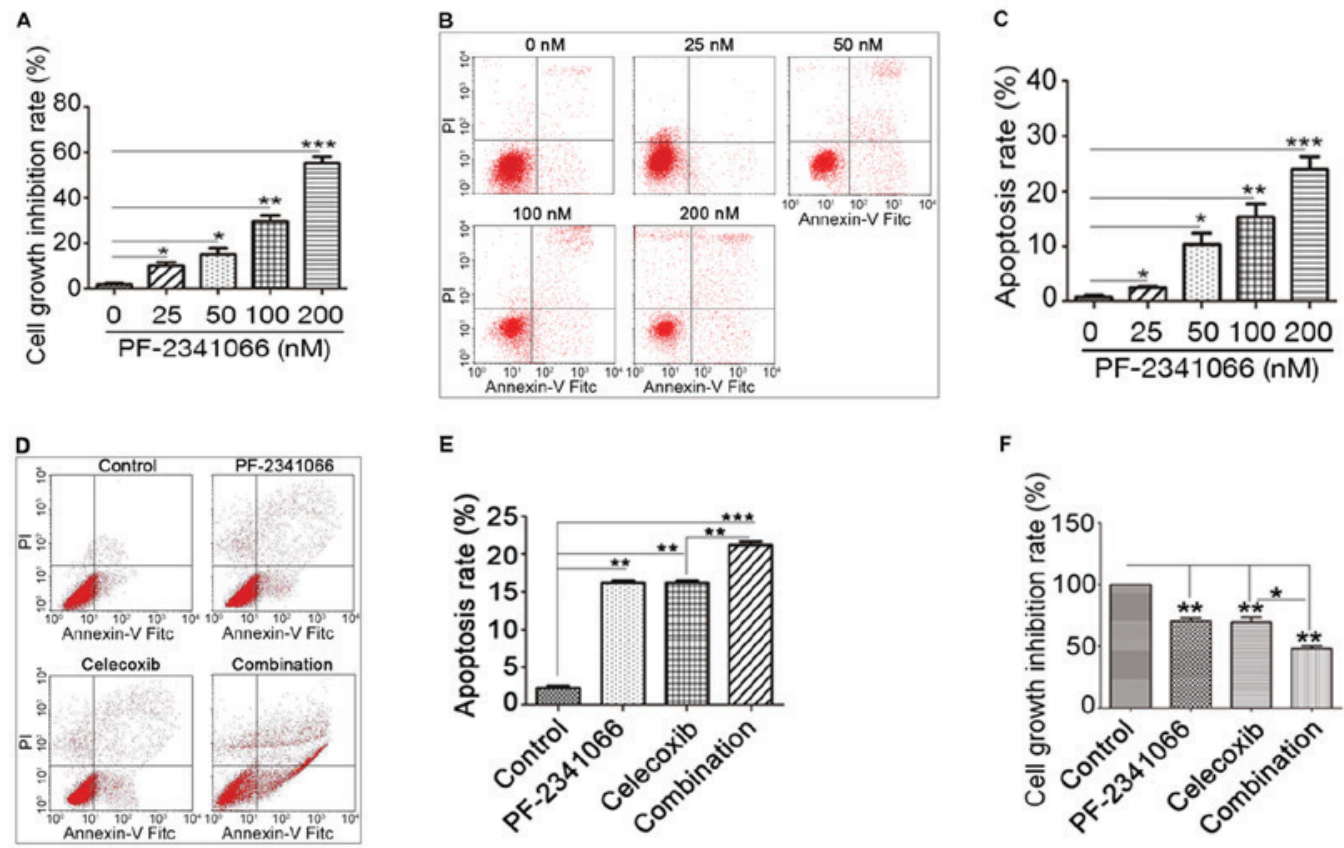

Figure 3. Effects of PF-2341066 and celecoxib on proliferation and apoptosis in QBC939 cells. Cells were treated with 0, 25, 50, 100 and $200 \mathrm{nM}$ PF-2341066. (A) Cell growth inhibition and (B) apoptosis were assessed using MTT and flow cytometry, respectively. (C) Cells in early and late apoptosis were summed to give the apoptosis rate. Cells were treated with $100 \mathrm{nM}$ PF-2341066 $+100 \mu \mathrm{M}$ celecoxib and (D) apoptosis was measured using flow cytometry. (E) Cells in early and late apoptosis were summed to give the apoptosis rate. (F) Cell growth inhibition was determined using an MTT assay. ${ }^{*} \mathrm{P}<0.05,{ }^{* *} \mathrm{P}<0.01$ and ${ }^{* * * *} \mathrm{P}<0.001$. FITC, fluorescein isothiocyanate; PI, propidium iodide; Combination, treatment with $100 \mathrm{nM} \mathrm{PF}-2341066+100 \mu \mathrm{M}$ celecoxib.
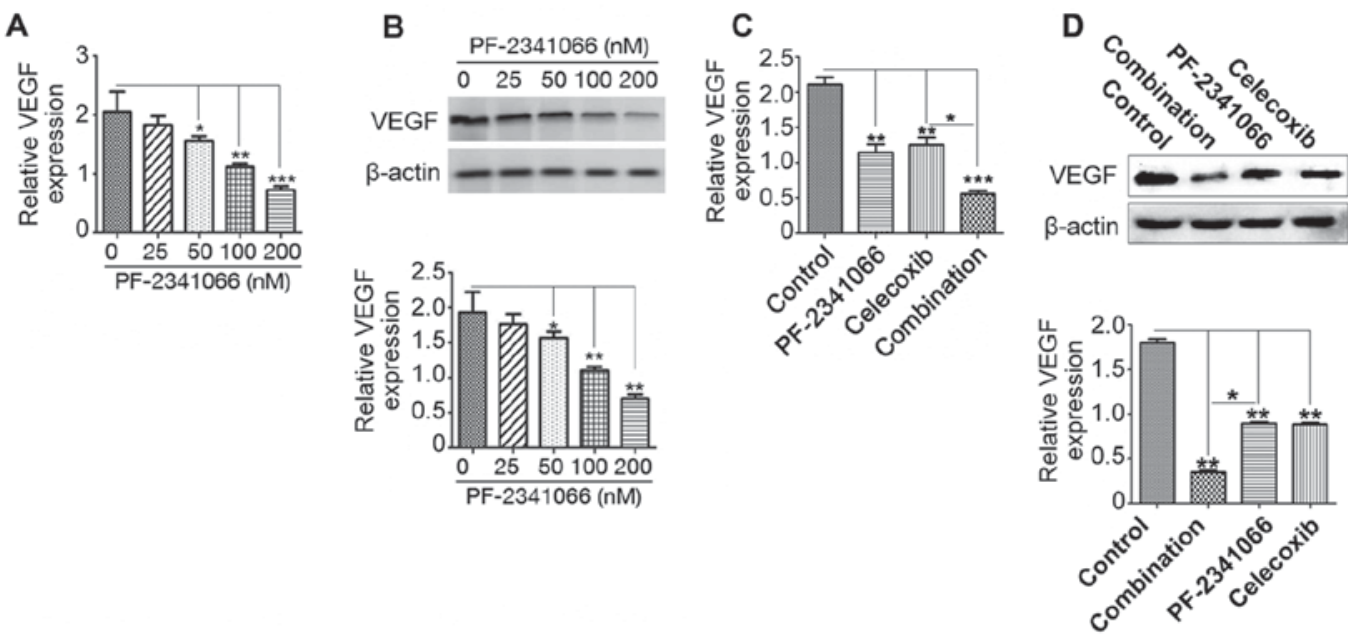

Figure 4. Expression of VEGF in QBC939 cells following treatment with PF-2341066 and celecoxib. Following treatment with 0, 25, 50, 100 and $200 \mathrm{nM}$ PF-2341066, VEGF (A) mRNA and (B) protein expression was measured using RT-qPCR and western blotting, respectively. Cells were treated with control, $100 \mathrm{nM}$ PF-2341066, $100 \mu \mathrm{M}$ celecoxib or $100 \mathrm{nM}$ PF-2341066 + $100 \mu \mathrm{M}$ celecoxib and VEGF (C) mRNA and (D) protein expression was assessed using RT-qPCR and western blotting, respectively. ${ }^{*} \mathrm{P}<0.05,{ }^{* *} \mathrm{P}<0.01$ and ${ }^{* * * *} \mathrm{P}<0.001$. VEGF, vascular endothelial growth factor; RT-qPCR, reverse transcription-quantitative polymerase chain reaction; Combination, treatment with $100 \mathrm{nM}$ PF-2341066 $+100 \mu \mathrm{M}$ celecoxib.

angiogenesis and metastasis in cholangiocarcinoma, the expression of VEGF in QBC939 cells was measured following treatment with PF-2341066 and celecoxib. VEGF mRNA and protein expression was downregulated by PF-2341066 in a dose-dependent manner (Fig. 4A and B). Furthermore, this inhibition was significantly increased by combined treatment with PF-2341066 and celecoxib (Fig. 4C and D). These results suggest that $\mathrm{PF}-2341066$ and celecoxib may restrict the development of cholangiocarcinoma by suppressing VEGF-mediated angiogenesis and tumor metastasis.

\section{Discussion}

Previous studies have demonstrated that c-Met is expressed in colon cancer, gastric cancer, esophageal cancer, pancreatic cancer, thyroid cancer and medulloblastoma (16,17). c-Met expression is positively correlated with HGF, tumor angiogenesis and poor clinical outcome in patients with tumors (18). c-Met expression was increased in tumor tissues compared with NT and may activate the downstream signal transduction pathway to affect proliferation, differentiation and apoptosis 
in tumor cells (19). In the present study it was revealed that c-Met is highly expressed in HCWC compared with NT, which suggests that c-Met may serve an important role in the development of HCWC. A previous study reported that c-Met is an important treatment target for cholangiocarcinoma (5), which supports the results herein. The c-Met inhibitor PF-2341066 is an ATP competitive small molecule compound; it has good biological availability and high water solubility (4). PF-2341066 is able to inhibit the c-Met signaling pathway by suppressing c-Met phosphorylation (4). In the present study, it was also demonstrated to inhibit c-Met expression at the mRNA and protein levels in QBC939 cells. According to the results of the present study, $\mathrm{PF}-2341066$ significantly inhibited cell proliferation and promoted cell apoptosis. Thus suggests that PF-2341066 may restrict the development of HCWC by downregulating c-Met and its downstream signaling.

$\mathrm{COX}$ is a major rate limiting enzyme in the synthesis of prostaglandin and is able to metabolize arachidonic acid into a variety of prostaglandin products, including prostaglandin $\mathrm{E} 2$, to induce a number of biological effects. It has previously been reported that high COX-2 expression is associated with the occurrence of malignant tumors and precancerous lesions $(20,21)$, including breast cancer (22), colon cancer (23), lung cancer (24), gastric cancer (25) and esophageal cancer (26). The selective COX-2 inhibitor celecoxib is a non-steroidal anti-inflammatory agent that is able to inhibit tumor cell proliferation and induce apoptosis $(27,28)$. The results of the present study revealed that celecoxib significantly downregulates the expression of COX-2 at the mRNA and protein levels. When QBC939 cells were co-treated with celecoxib and PF-2341066, the effects on cell proliferation and apoptosis were greater than those observed with PF-2341066 alone. It may therefore by hypothesized that combined treatment with celecoxib and PF-2341066 may inhibit the development of HCWC by regulating the c-Met and COX-2-mediated common pathway or the cross-talk between these two pathways.

It is possible to inhibit the growth and metastasis of tumors by targeting and reducing tumor angiogenesis. Tumor angiogenesis is a multi-step process and blocking any one of the steps in this process, including inhibiting angiogenesis factor binding, destruction of the adhesion model or blocking the signal transduction pathway may prevent the formation of blood vessels in the tumor (29). VEGF was first identified in 1989 by Go Spodarwia; it was similar to vascular permeability factor and was able to promote the mitosis of vascular endothelial cells (30). VEGF promotes the proliferation of vascular endothelial cells, increases vascular permeability and maintains the integrity of blood vessels by binding to its receptor $(15,31,32)$. In the present study, it was demonstrated that PF-2341066 alone and in combination with celecoxib may inhibit the expression of VEGF at the transcription and translation levels in QBC939 cells. The results of the present study suggest that PF-2341066 and celecoxib may be an effective treatment for HCWC, which functions by restricting tumor angiogenesis.

\section{Acknowledgements}

The authors thank the nurses at the Hunan Provincial People's Hospital (Changsha, China) for their assistance in the collection of samples.

\section{Funding}

This work was supported by the research fund of Hunan provincial health and Family Planning Commission (grant no. C2016005) and the scientific research fund of Changsha Municipal Science and Technology Bureau (grant no. k15zd006-34).

\section{Availability of data and materials}

All data generated or analyzed during this study are included in this published article.

\section{Authors' contributions}

CCh designed the research, performed the experiments, analyzed the data and wrote the manuscript. DY designed and directed the research. QZ, LL and CCa performed the experiments and analyzed data. All authors read and approved the final manuscript.

\section{Ethics approval and consent to participate}

The present study was performed in strict accordance with the approval and recommendations of the Committee for Care and Use in Clinical Study of Hunan Provincial People's Hospital (C2016005). All patients provided written informed consent.

\section{Consent for publication}

The patients have provided written informed consent for the publication of all data and accompanying images.

\section{Competing interests}

The authors declare no conflict of interest.

\section{References}

1. Haga H, Yan IK, Takahashi K, Wood J, Zubair A and Patel T: Tumour cell-derived extracellular vesicles interact with mesenchymal stem cells to modulate the microenvironment and enhance cholangiocarcinoma growth. J Extracell Vesicles 4: 24900, 2015.

2. Jiang WG, Martin TA, Parr C, Davies G, Matsumoto K and Nakamura T: Hepatocyte growth factor, its receptor, and their potential value in cancer therapies. Crit Rev Oncol Hematol 53: 35-69, 2005.

3. Sandler AB and Dubinett SM: COX-2 inhibition and lung cancer. Semin Oncol 31 (2 Suppl 7): S45-S52, 2004.

4. Zou HY, Li Q, Lee JH, Arango ME, McDonnell SR, Yamazaki S, Koudriakova TB, Alton G, Cui JJ, Kung PP, et al: An orally available small-molecule inhibitor of c-met, PF-2341066, exhibits cytoreductive antitumor efficacy through antiproliferative and antiangiogenic mechanisms. Cancer Res 67: 4408-4417, 2007.

5. Socoteanu MP, Mott F, Alpini G and Frankel AE: c-Met targeted therapy of cholangiocarcinoma. World J Gastroenterol 14: 2990-2994, 2008.

6. Gandou C, Harada K, Sato Y, Igarashi S, Sasaki M, Ikeda H and Nakanuma Y: Hilar cholangiocarcinoma and pancreatic ductal adenocarcinoma share similar histopathologies, immunophenotypes, and development-related molecules. Hum Pathol 44: 811-821, 2013.

7. Ferrucci A, Moschetta M, Frassanito MA, Berardi S, Catacchio I, Ria R, Racanelli V, Caivano A, Solimando AG, Vergara D, et al: A HGF/cMET autocrine loop is operative in multiple myeloma bone marrow endothelial cells and may represent a novel therapeutic target. Clin Cancer Res 20: 5796-5807, 2014. 
8. Klenke FM, Gebhard MM, Ewerbeck V, Abdollahi A, Huber PE and Sckell A: The selective Cox-2 inhibitor Celecoxib suppresses angiogenesis and growth of secondary bone tumors: An intravital microscopy study in mice. BMC Cancer 6: 9, 2006.

9. Zhou YY, Hu ZG, Zeng FJ and Han J: Clinical profile of cyclooxygenase-2 inhibitors in treating non-small cell lung cancer: A meta-analysis of nine randomized clinical trials. PLoS One 11: e0151939, 2016.

10. Clapéron A, Mergey M, Nguyen Ho-Bouldoires TH, Vignjevic D, Wendum D, Chrétien Y, Merabtene F, Frazao A, Paradis V, Housset C, et al: EGF/EGFR axis contributes to the progression of cholangiocarcinoma through the induction of an epithelial-mesenchymal transition. J Hepatol 61: 325-332, 2014.

11. Hung TH, Li YH, Tseng CP,Lan YW, Hsu SC, Chen YH, Huang TT, Lai HC, Chen CM, Choo KB and Chong KY: Knockdown of c-MET induced apoptosis in ABCB1-overexpressed multidrug-resistance cancer cell lines. Cancer Gene Ther 22: 262-270, 2015.

12. Marti P, Stein C, Blumer T, Abraham Y, Dill MT, Pikiolek M, Orsini V, Jurisic G, Megel P, Makowska Z, et al: YAP promotes proliferation, chemoresistance, and angiogenesis in human cholangiocarcinoma through TEAD transcription factors. Hepatology 62: 1497-1510, 2015.

13. Kang YK, Muro K, Ryu MH, Yasui H, Nishina T, Ryoo BY, Kamiya Y, Akinaga S and Boku N: A phase II trial of a selective c-Met inhibitor tivantinib (ARQ 197) monotherapy as a secondor third-line therapy in the patients with metastatic gastric cancer. Invest New Drugs 32: 355-361, 2014.

14. Schmittgen TD and Livak KJ: Analyzing real-time PCR data by the comparative C(T) method. Nat Protoc 3: 1101-1108, 2008

15. Hicklin DJ and Ellis LM: Role of the vascular endothelia growth factor pathway in tumor growth and angiogenesis. J Clin Oncol 23: 1011-1027, 2005.

16. Rizvi S and Gores GJ: Pathogenesis, diagnosis, and management of cholangiocarcinoma. Gastroenterology 145: 1215-1229, 2013.

17. Patel MB, Pothula SP, Xu Z, Lee AK, Goldstein D, Pirola RC Apte MV and Wilson JS: The role of the hepatocyte growth factor/c-MET pathway in pancreatic stellate cell-endothelial cell interactions: Antiangiogenic implications in pancreatic cancer. Carcinogenesis 35: 1891-1900, 2014

18. Park HJ, Kim K, Paik JH, Chie EK, Kim S, Jang JY, Kim SW, Han SW, Oh DY, Im SA, et al: Is c-Met oncoprotein expression an adverse prognosticator in extrahepatic bile duct cancer treated with curative resection followed by adjuvant chemoradiotherapy? Clin Transl Oncol 18: 625-631, 2016.

19. Wu GS, Zou SQ, Liu ZR, Tang ZH and Wang JH: Celecoxib inhibits proliferation and induces apoptosis via prostaglandin E2 pathway in human cholangiocarcinoma cell lines. World J Gastroenterol 9: 1302-1306, 2003
20. Hosomi Y, Yokose T, Hirose Y, Nakajima R, Nagai K, Nishiwaki Y and Ochiai A: Increased cyclooxygenase 2 (COX-2) expression occurs frequently in precursor lesions of human adenocarcinoma of the lung. Lung Cancer 30: 73-81, 2000.

21. Soslow RA, Dannenberg AJ, Rush D, Woerner BM, Khan KN, Masferrer J and Koki AT: COX-2 is expressed in human pulmonary, colonic, and mammary tumors. Cancer 89: 2637-2645, 2000.

22. Ristimäki A, Sivula A, Lundin J, Lundin M, Salminen T, Haglund C, Joensuu $\mathrm{H}$ and Isola J: Prognostic significance of elevated cyclooxygenase- 2 expression in breast cancer. Cancer Res 62: 632-635, 2002.

23. Tsujii M, Kawano S and DuBois RN: Cyclooxygenase-2 expression in human colon cancer cells increases metastatic potential. Proc Natl Acad Sci USA 94: 3336-3340, 1997.

24. Hida T, Yatabe Y, Achiwa H, Muramatsu H, Kozaki K, Nakamura S, Ogawa M, Mitsudomi T, Sugiura T and Takahashi T: Increased expression of cyclooxygenase 2 occurs frequently in human lung cancers, specifically in adenocarcinomas. Cancer Res 58: 3761-3764, 1998.

25. Ristimäki A, Honkanen $N$, Jänkälä $H$, Sipponen $P$ and Härkönen M: Expression of cyclooxygenase-2 in human gastric carcinoma. Cancer Res 57: 1276-1280, 1997.

26. Zimmermann KC, Sarbia M, Weber AA, Borchard F, Gabbert HE and Schrör K: Cyclooxygenase-2 expression in human esophageal carcinoma. Cancer Res 59: 198-204, 1999.

27. Alshafie GA, Abou-Issa HM, Seibert K and Harris RE: Chemotherapeutic evaluation of Celecoxib, a cyclooxygenase-2 inhibitor, in a rat mammary tumor model. Oncol Rep 7: 1377-1381, 2000.

28. Leahy KM, Ornberg RL, Wang Y, Zweifel BS, Koki AT and Masferrer JL: Cyclooxygenase-2 inhibition by celecoxib reduces proliferation and induces apoptosis in angiogenic endothelial cells in vivo. Cancer Res 62: 625-631, 2002.

29. Balansky R, Ganchev G, Iltcheva M, Nikolov M, La Maestra S, Micale RT, D'Agostini F, Steele VE and De Flora S: Modulation by licofelone and celecoxib of experimentally induced cancer and preneoplastic lesions in mice exposed to cigarette smoke. Curr Cancer Drug Targets 15: 188-195, 2015.

30. Couffinhal T, Kearney M, Witzenbichler B, Chen D, Murohara T, Losordo DW, Symes J and Isner JM: Vascular endothelial growth factor/vascular permeability factor (VEGF/VPF) in normal and atherosclerotic human arteries. Am J Pathol 150: 1673-1685, 1997.

31. Yancopoulos GD, Davis S, Gale NW, Rudge JS, Wiegand SJ and Holash J: Vascular-specific growth factors and blood vessel formation. Nature 407: 242-248, 2000.

32. Lee SH, Jeong D, Han YS and Baek MJ: Pivotal role of vascular endothelial growth factor pathway in tumor angiogenesis. Ann Surg Treat Res 89: 1-8, 2015. 